\title{
Avaliação de imagens multipolarizadas de radar (banda L) do sensor SAR- R99B para mapeamento geológico no Baixo Vale do Curaçá, Bahia
}

\author{
Tiago Nunes Rabelo ${ }^{1}$, Waldir Renato Paradella ${ }^{1}$, Athos Ribeiro dos Santos ${ }^{1}$, \\ Sheila Soraya Alves Knust ${ }^{2}$ \& José Claudio Mura ${ }^{3}$
}

\begin{abstract}
Resumo Aplicações geológicas com imagens de radar não tem sido comuns em ambientes semi-áridos do país. Neste contexto, o objetivo desta investigação foi a avaliação de imagens multipolarizadas em banda L do sensor aeroportado SAR-R99B (SIVAM-CENSIPAM) em mapeamento geológico no baixo Vale do Curaçá, um importante distrito cuprífero no estado da Bahia. A área de estudo apresenta um relevo plano, com vegetação moderada à esparsa de caatinga e solos residuais pouco espessos, que refletem com boa aproximação as variações litotípicas do substrato geológico. Estas características favorecem a avaliação de imagens SAR em mapeamento geológico. A área de estudo é parte do Cráton São Francisco, sendo composta por rochas paleoproteozóicas granulíticas e gnáissicas e uma sequiência de intrusivas máfico-ultramáficas. Subordinadamente ocorrem rochas metassedimentares de idade neoproterozóica. Nesta pesquisa foram avaliadas imagens multipolarizadas em banda L (L-HH, L-VV, L-HV), no formato de amplitude e resolução espacial de 6 metros. Os procedimentos de fotogeologia foram aplicados utilizando-se a interface gráfica de visualização e realces digitais disponíveis no pacote FOCUS (software PCI Geomatics) calibrados com dados bibliográficos e de campo. Os resultados da fotointerpretação geológica mostraram que a polarização L-VV apresentou o melhor desempenho na discriminação de litologias dado por um maior contraste tonal/textural das unidades de maior ocorrência na área (mica-xistos, quartzo-feldspato gnaisses) e por um melhor detalhamento das unidades de ocorrências mais restritas (mármores, máfico-ultramáficas). Quanto à caracterização estrutural, as três imagens polarizadas tiveram um desempenho bastante similar, com uma pequena desvantagem da polarização L-HH, revelando a importância do componente vertical da polarização nas imagens L-VV e L-HV no realce das feições estruturais. A excelente qualidade radiométrica dos dados SAR calibrados, a elevada resolução espacial, e a boa sensibilidade das respostas às variações de macro, micro-topografia e umidade, determinaram os resultados dessa análise.
\end{abstract}

Palavras-chave: radar, SAR-R99B (SIVAM-CENSIPAM), Vale do Curaçá (BA), banda L multipolarizada.

\begin{abstract}
Evaluation of multipolarized L-band radar images of the sensor SAR-R99B for geological mapping in the Low Curaçá Valley. In the tropical semi-arid environment of Brazil geological applications with radar are still rare. The objective of this research was the evaluation of multipolarized L-band radar images acquired by the sensor SAR-R99B (SIVAM-CENSIPAM) for geological mapping in the lower Curaçá valley, an important $\mathrm{Cu}$-rich district of the Bahia state. The test-site is characterized by a flat terrain, with moderate to sparse caatinga vegetation and shallow residual soils closely related to changes in the geological substratum. These characteristics favor the evaluation of SAR images for geological mapping. The test-site is part of the São Francisco Craton, and encompasses paleoproterozoic granulitic and gneissic rocks and an intrusive sequence of mafics and ultramafics. Subordinately, metasediments with neoproterozoic ages also occur. In this investigation it was evaluated multipolarized L-band images (L-HH, L-VV, L-HV), amplitude format with 6-meter of spatial resolution. The photogeological procedures were applied using the graphical interface of viewing and digital enhancements available in the FOCUS package (PCI Geomatics software), calibrated with bibliographic and field information. The results of the photogeological interpretation showed that L-VV presented the best performance in the discrimination of lithologies given by a higher tonal/textural contrast of more frequent units (mica- schists, quartz-feldspar gneiss) and a better detailment of more restricted ones (marbles, mafic-ultramafics). Regarding the structural characterization, the three polarizations showed a similar performance, with a slightly disadvantage of L-HH revealing the importance of the vertical component of polarization in the L-VV and L-HV images in the enhancement of structural features. The excellent radiometric quality of calibrated SAR data, high spatial resolution and good response sensitivity to variations of macro, micro-topography and moisture were responsible for the results of the analysis.
\end{abstract}

Keywords: radar, SAR-R99B (SIVAM-CENSIPAM), Curaçá Valley (Bahia), multipolarized L-band.

1- Instituto Nacional de Pesquisas Espaciais (INPE), Divisão de Sensoriamento Remoto (DSR), São José dos Campos (SP), Brasil. E-mail: tiago.rabelo@vilaricaconsultoria.com.br; waldir@ltid.inpe.br; athos@ltid.inpe.br

2- Gerência de Geologia e Recursos Minerais - Serviço Geológico do Brasil - CPRM, Goiânia (GO), Brasil. E-mail: sknust@gmail.com

3- Instituto Nacional de Pesquisas Espaciais (INPE) - Divisão de Processamento de Imagens (DPI), São José dos Campos (SP), Brasil.

E-mail: mura@dpi.inpe.br 
INTRODUÇÃO Nas duas últimas décadas, imagens SAR (Synthetic Aperture Radar) obtidas por sistemas orbitais (JERS-1, RADARSAT-1, etc.) têm sido utilizadas com grande ênfase em aplicações geológicas em ambientes de floresta tropical úmida da Amazônia. Estas aplicações têm sido desenvolvidas com dados unidimensionais (única data, única freqüência, única polarização e único intervalo de incidência), adaptando técnicas de fotointerpretação às características do imageamento SAR (imagens de amplitude e uma polarização). O enfoque tem sido dado a estudos estruturais e tectônicos (Veneziani et al. 2004), a estereoscopia (Santos et al. 1999, 2003), a integração de radar com dados de sensores ópticos e aerogeofísica (Paradella et al. 1997, 1998, 2000, 2005, Pedroso et al. 2001, Cunha et al. 2006, Teruiya et al. 2008), entre outros. Por outro lado, tem sido rara a utilização deste tipo de imagens em aplicações geológicas fora do ambiente amazônico.

O Vale do Curaçá (VC) representa importante distrito cuprífero localizado no norte do estado da Bahia. A região possui um longo histórico em pesquisas de prospecção geológica, sendo conhecida pelas suas mineralizações de cobre associadas às rochas máficoultramáficas, que perfazem cerca de três centenas de corpos potencialmente mineralizados (Delgado \& Souza 1975, Lindenmayer 1981, Hasui et al. 1982, D'elRey Silva 1985, 1996). O clima na área é semi-árido, com pluviosidade (500-700 mm/ano) de distribuição bastante irregular. A topografia é plana, marcada por uma superfície de pediplanação (350-430 m) onde sobressaem os inselbergs das serras Redonda $(560 \mathrm{~m}) \mathrm{e}$ Canabrava $(750 \mathrm{~m})$. A vegetação é, em grande parte, esparsa típica de caatinga. A flutuação anual nas condições climáticas, especialmente as chuvas, resulta em variações na fisionomia e fenologia da cobertura vegetal, com a flora exibindo uma alta seletividade em relação ao tipo de solo. Os solos são residuais rasos, variam de arenosos a argilosos e, com freqüência, pela cor e textura, apresentam relação direta com o substrato rochoso (Paradella \& Vitorello 1995).

Através de cooperação entre o INPE (Instituto Nacional de Pesquisas Espaciais) e a DLR (Agência Aeroespacial da Alemanha), um estudo de viabilidade para a construção de um satélite de radar em banda $\mathrm{L}$ (MAPSAR-Multi-Application Purpose SAR) encontrase em desenvolvimento. O MAPSAR está sendo proposto com atributos inovadores de elevada resolução espacial, polarimetria, interferometria e estereoscopia (Schroder et al. 2005). Uma das etapas importantes neste programa envolveu a aquisição de dados de radar polarimétrico com o sensor aeroportado SAR-R99B do SIVAM-CENSIPAM (Sistema de Vigilância da Amazônia - Centro Gestor e Operacional do Sistema de Proteção da Amazônia), em várias áreas do território nacional. Tais dados serviram de base na simulação do radar do satélite MAPSAR (Mura et al. submetido). Neste contexto, este trabalho apresenta os primeiros resultados da avaliação geológica das imagens originais do SAR-R99B do recobrimento inédito realizado no VC em 2005 (Fig. 1). Resultados de produtos simulados
MAPSAR podem ser vistos em Rabelo et al. (2007).

CONTEXTO GEOLÓGICO A área investigada engloba setores do embasamento pertencente ao Cráton do São Francisco e suas coberturas (Almeida 1977). O Cráton do São Francisco no estado da Bahia é o resultado de colisões de quatro segmentos crustais (Blocos Gavião, Jequié, Serrinha e Itabuna-Salvador-Curaçá) ocorridos no final do Paleoproterozóico, justapondo terrenos arqueanos (Bloco Gavião, núcleos TTG, seqüência Contendas Mirante, Complexo Jequié, núcleo Serrinha, etc) e paleoproterozóicos (Grupo Jacobina, Greenstone Belts do Rio Itapicuru e Capim, etc.) através de grandes descontinuidades tectônicas. Essas colisões resultaram na formação de cinturões móveis polideformados, como o Orógeno Itabuna-Salvador-Curaçá onde se situa a área de estudo (Figs. 2A e 2B). No Mesoproterozóico depositaram-se os sedimentos do Supergrupo Espinhaço em um rift abortado de direção N-S. No Neoproterozóico depositaram-se, sobre os sedimentos do Espinhaço e em parte do embasamento arqueano/paleoproterozóico, os sedimentos glaciais e pelitico-carbonáticos paraplataformais do Supergrupo São Francisco. No final do Proterozóico formaram-se os cinturões dobrados, como resultado de colisões nas margens do Cráton do São Francisco. O Paleozóico é marcado por extensa cobertura plataformal (Teixeira et al. 2000, Barbosa \& Sabaté 2002, 2003, 2004, Barbosa et al. 2003).

As unidades litológicas da área de estudo, localizada em setor no baixo VC, compreendem associações de rochas granulíticas, gnáissicas e migmatíticas de idades que variam do Arqueano ao Paleoproterozóico, rochas máfico-ultramáficas associadas e granitóides de idades paleoproterozóicas e uma cobertura neoproterozóica constituída por calcários, mármores e xistos (Delgado \& Souza 1975, Angelim \& Kosin 2001) (Fig. 3). As rochas gnáissico-granulíticas são cortadas por corpos intrusivos máfico-ultramáficos mineralizados em cobre e orientados preferencialmente segundo N-S. Sulfetos maciços e disseminados ocorrem principalmente em piroxenitos e, com menor importância econômica, os sulfetos encontram-se fracamente disseminados em noritos, gabro-noritos e anortositos (Lindenmayer 1981, Hasui et al. 1982).

DADOS DO SENSOR SAR-R99B O sensor de radar SAR-R99B foi desenvolvido pela empresa canadense MacDonald Dettwiler, sob contrato da Raytheon Systems Corporation, e opera instalado em aeronave modificada da série EMBRAER-145. Três sistemas idênticos foram adquiridos neste contrato e estão em diferentes estágios de operacionalidade com uso das bandas X $(3,1$ $\mathrm{cm}$ de comprimento de onda ou freqüência de $9,88 \mathrm{GHz}$ ) e L (23,9 cm de comprimento de onda ou freqüência de $1,27 \mathrm{GHz}$ ). O SAR-R99B possui três modos de imageamento: um modo de mapeamento nas bandas $\mathrm{X} \mathrm{e} \mathrm{L}$, um modo de vigilância com variações na banda X-HH (Spotlight SAR, A2A, WAS) e um modo interferométrico (InSAR) na banda X-HH. No modo de mapeamento, seis opções de combinações de freqüências X e L estão 


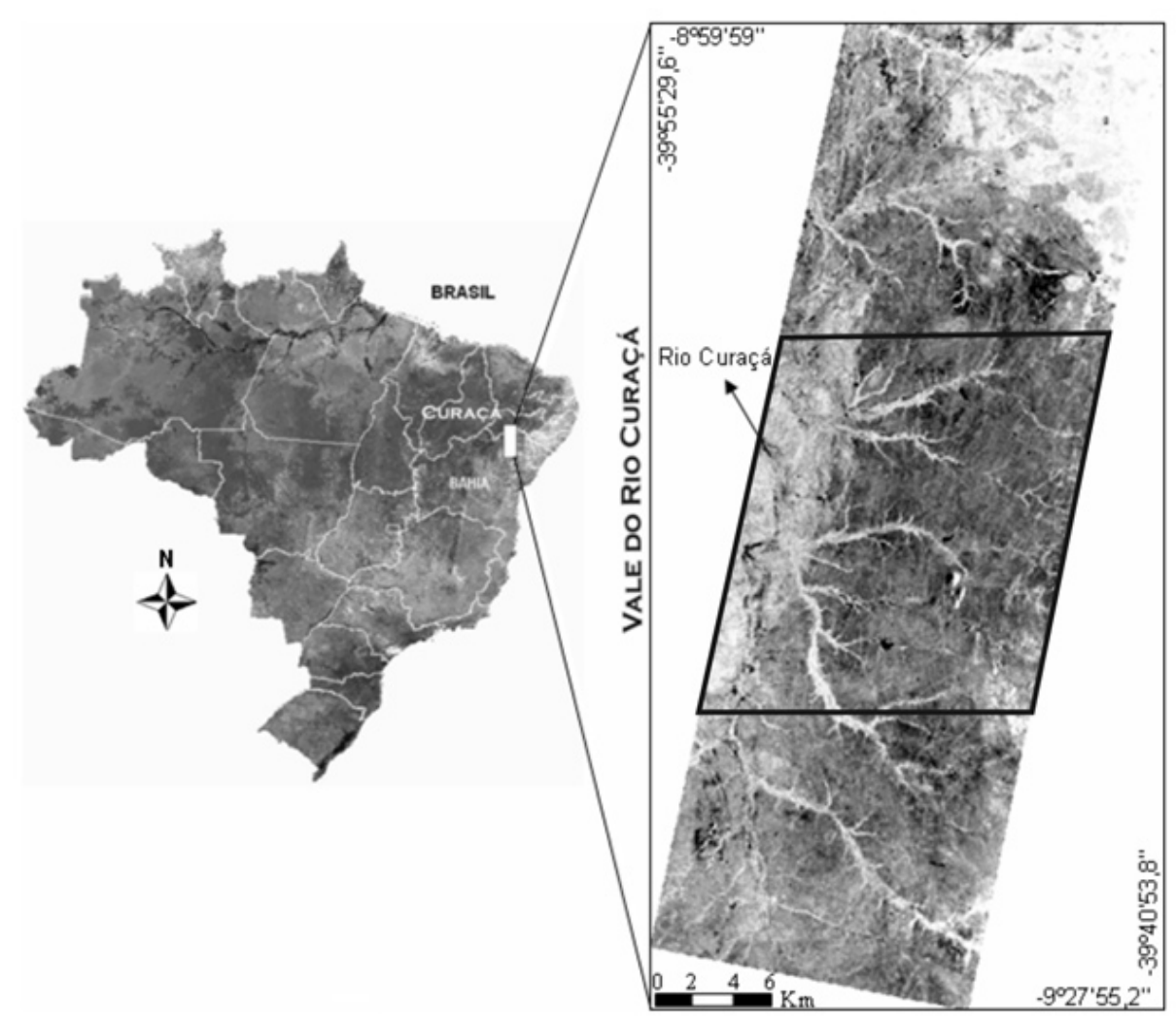

Figura 1 - Localização da área de estudo no Vale do Curaçá (em detalhe imagem SAR-R99B em banda L-VV).

disponíveis: quad-L (imagens de amplitude e fase entre canais) + single X; dual L + single X; InSAR $(\mathrm{X}-\mathrm{HH})+$ single L; quad L; single L + single X e INSAR + quad-L. Utilizando somente as configurações em banda L são possíveis imageamentos com 3, 6, ou $18 \mathrm{~m}$ de resolução espacial nominal e larguras de faixas de recobrimento (swath) de 20, 40 e $120 \mathrm{~km}$. Aquisições simultâneas em banda X interferométrica e L polarimétrica são também possíveis, com seis canais de dados produzidos simultaneamente (Goulding et al. 2001). Este notável potencial de imageamento tem sido ainda muito pouco explorado em aplicações geológicas no país.

A aquisição dos dados SAR-R99B na área-teste foi conduzida em 30 de junho de 2005. O modo A1 Qual L+ X (L polarimétrica + X-HH) foi o utilizado, sendo nesta pesquisa analisados somente os dados multipolarizados representados por imagens de amplitude, 16 bits não sinalizados, bandas L-HH, L-VV e L-HV, resolução espacial de 6 metros, intervalo de incidência de $52^{\circ}$ (near-range) a $71^{\circ}$ (far-range), processamento em 5 looks, e largura da faixa (swath) de 20 quilômetros. O recobrimento foi orientado segundo a trajetória prevista de órbita descendente do MAPSAR com azimute de visada de $282^{\circ}$ (visada para W). Os dados foram calibrados radiometricamente e polarimetricamente, segundo os procedimentos descritos por Mura et al. (2007). Basicamente, na correção de padrão de antena foi usado o modelo multiplicativo através de função de ajuste definida sobre áreas de respostas homogêneas do inicio (near-range) ao final da faixa (far-range). A ca- libração polarimétrica foi baseada no método proposto por Quegan (1984). As imagens foram geometricamente corrigidas para a projeção UTM (Universal Transversal Mercator) e para o datum SAD-69 (South American Datum) através de equação polinomial de primeiro grau e interpolação de vizinho mais-próximo.

FUNDAMENTAÇÃO E MÉTODOS As imagens de radar fornecem informações sobre as características geométricas e elétricas da superfície do terreno. O radar é sensível à geometria superficial controlada pela macro-topografia (variações de declividade do terreno em escala decamétrica) e pela micro-topografia (rugosidade superficial na escala de comprimento de onda do SAR). O radar também é sensível às propriedades elétricas superficiais, que são muito dependentes da umidade do solo. A discriminação de litologias por assinaturas do sinal de microondas retroespalhado é possível quando variações composicionais implicarem em rugosidades superficiais distintas (Ford et al. 1998). Neste sentido, pesquisas têm investigado a influência da multipolarização na discriminação de rochas e produtos de alteração em ambientes desérticos (Daily et al. 1978, Schaber \& Berlin 1980). Uma análise dessas contribuições permite concluir que imagens de polarização paralela (HH, VV) são mais sensíveis à rugosidade superficial para componentes de superfície que satisfaçam à ressonância Bragg (rugosidade da micro-topografia aproximadamente igual ao comprimento de onda do SAR), enquanto que imagens de polarização cruzada (HV, 


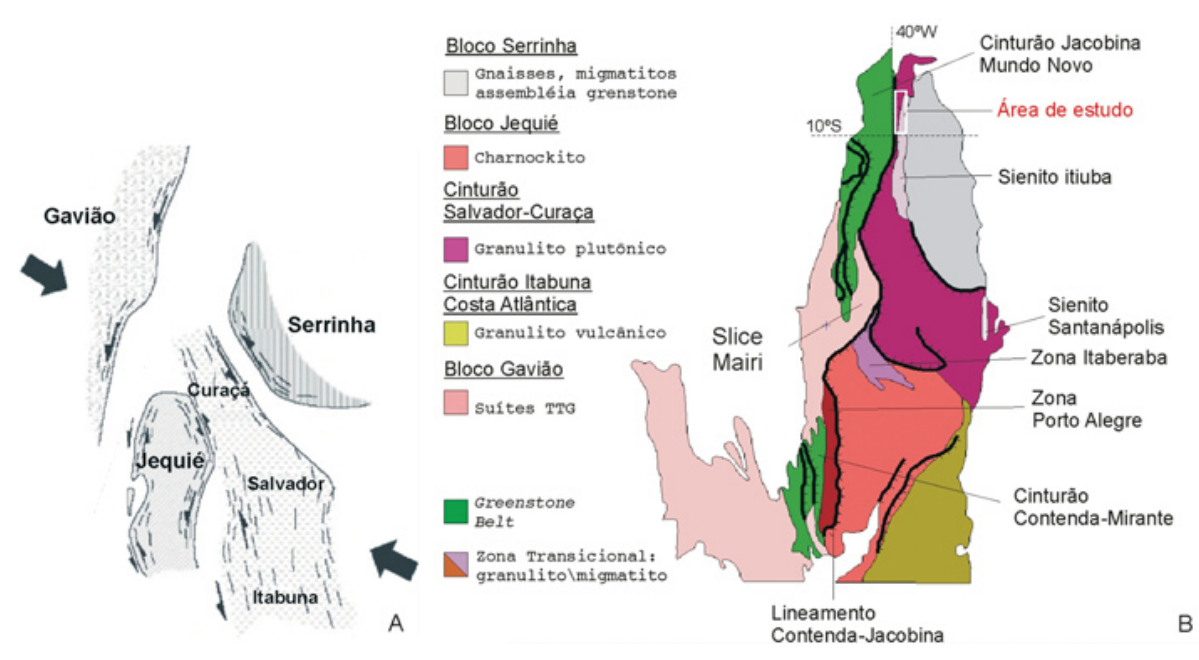

Figura 2 - Evolução e estruturação da porção $N$ do Cráton São Francisco. (A) Posição relativa dos blocos antes das colisões paleoproterozóicas. Fonte: Barbosa \& Sabaté (2002) e (B) estruturação da porção norte do Cráton São Francisco. Fonte: Teixeira et al. (2000), após Sabaté \& Cunha (1998).

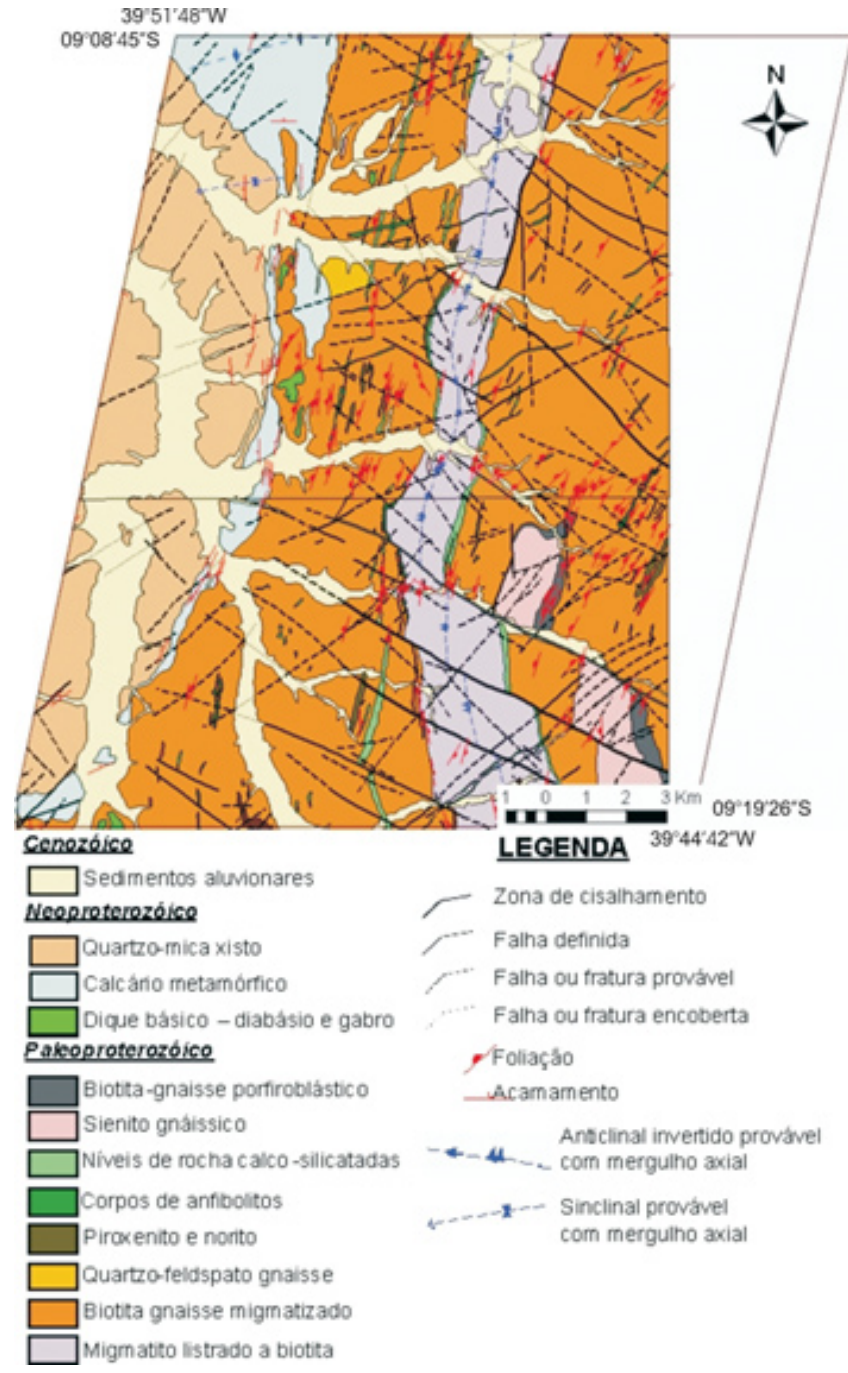

Figura 3 - Cartografia geológica de grande parte da área de estudo baseada em mapeamento de detalhe (1: 50.000) do setor norte do VC. Fonte: Delgado \& Souza (1975).
VH) são mais controladas pela rugosidade superficial média do terreno. Sob pequena incidência, a imagem razão de polarizações paralelas (HH/VV) é mais dependente da geometria de observação, da declividade e das propriedades dielétricas, e menos sensível à rugosidade superficial. Para incidências entre $20^{\circ}$ e $65^{\circ}$, o retroespalhamento na polarização paralela é menos sensível à variação da declividade na direção perpendicular ao plano de incidência, em comparação com a polarização cruzada. A polarização HH é a menos sensível aos efeitos de constante dielétrica em comparação com as polarizações VV, HV e VH. Investigações com dados multipolarizados em banda L mostraram correlações significativas entre retroespalhamento e diferenças de alteração de superfície, idades de rochas, umidade, descontinuidades de subsuperfície e densidade de cobertura vegetal, permitindo o mapeamento de características únicas de superfícies (Evans et al. 1986).

As imagens em amplitude, realçadas individualmente por Ampliação Linear de Contraste (ALC), combinadas por composição colorida das bandas multipolarizadas e por Transformação por Componentes Principais (TCP), foram analisadas visualmente e fotointerpretadas na tela de um monitor de computador, utilizando-se a interface gráfica de visualização do software FOCUS, com uso de algoritmos de processamento digital de imagens e ferramentas auxiliares de análise, extração e captura de dados (PCI Geomatics 2005). A fotointerpretação geológica foi baseada em critérios morfoestruturais estabelecidos para imagens ópticas de baixa resolução espacial (Veneziani \& Anjos 1982), adaptados às características peculiares das imagens SAR (Santos et al. 2001). O imageamento de radar pela visão oblíqua possibilita um ótimo realce morfológico (macro e micro-topografias). Os elementos texturais identificados nas imagens de radar (drenagem, relevo e tonalidade) foram ordenados e classificados segundo 
critérios morfoestruturais que permitiram sugerir uma associação com um significado geológico.

\section{RESULTADOS}

Fotointerpretação geológica das cenas multipolarizadas Nas cenas multipolarizadas utilizadas (Fig. 4) a drenagem (prioritariamente) e o relevo foram os elementos texturais mais importantes na análise da fotointerpretação geológica. A tonalidade das imagens foi também um elemento valioso na delimitação das diferentes unidades litotípicas. A área de pesquisa favorece um bom controle da variação tonal pelas características da macrorugosidade (declives suaves) e micro-topografia (rugosidade superficial), associada com variação de cobertura vegetal de caatinga e uma grande exposição de rochas e seus produtos de alteração (solos residuais).

No caso dos canais de drenagem, a tonalidade clara é causada pela associação de três fatores, que combinados em maior ou menor intensidade, contribuem para o alto retroespalhamento do sinal nas imagens multipolarizadas: (i) presença de afloramentos e blocos de rochas de várias dimensões, trazidos pelas precipitações que são breves, porém torrenciais, (ii) uma cobertura vegetal com estrato arbóreo de vegetação fo- tossinteticamente ativa, mesmo na época de estiagem, e (iii) presença de sedimentos arenosos que preservam a umidade. As variações de macro-topografia ligadas às ondulações suaves ou bruscas do relevo caracterizadas por quebras negativas e positivas (cristas) de direções aproximadas N-S e NE-SW tiveram uma importante contribuição na análise, principalmente na porção nordeste da área imageada.

Os elementos texturais de drenagem e de relevo identificados em cada uma das cenas polarizadas foram analisados segundo suas propriedades texturais (freqüência, feição linear, alinhamento, assimetria, tropia, quebra de relevo, uniformidade) e propriedades das formas (estrutura, grau de estruturação e ordem de estruturação) permitindo a delimitação de diferentes zonas homólogas (ZH's). As variações de tonalidade identificadas nas imagens possibilitaram também a delimitação de ZH's, considerando-se os critérios de intensidade, contraste e uniformidade de brilho e de forma.

Todas as informações extraídas dos elementos de imagem em cada polarização foram reunidas e integradas com o objetivo de gerar os mapas de fotoanálise e de alinhamentos. O mapa de fotoanálise da imagem de polarização L-HH (Fig. 5d) é constituído por doze ZH's
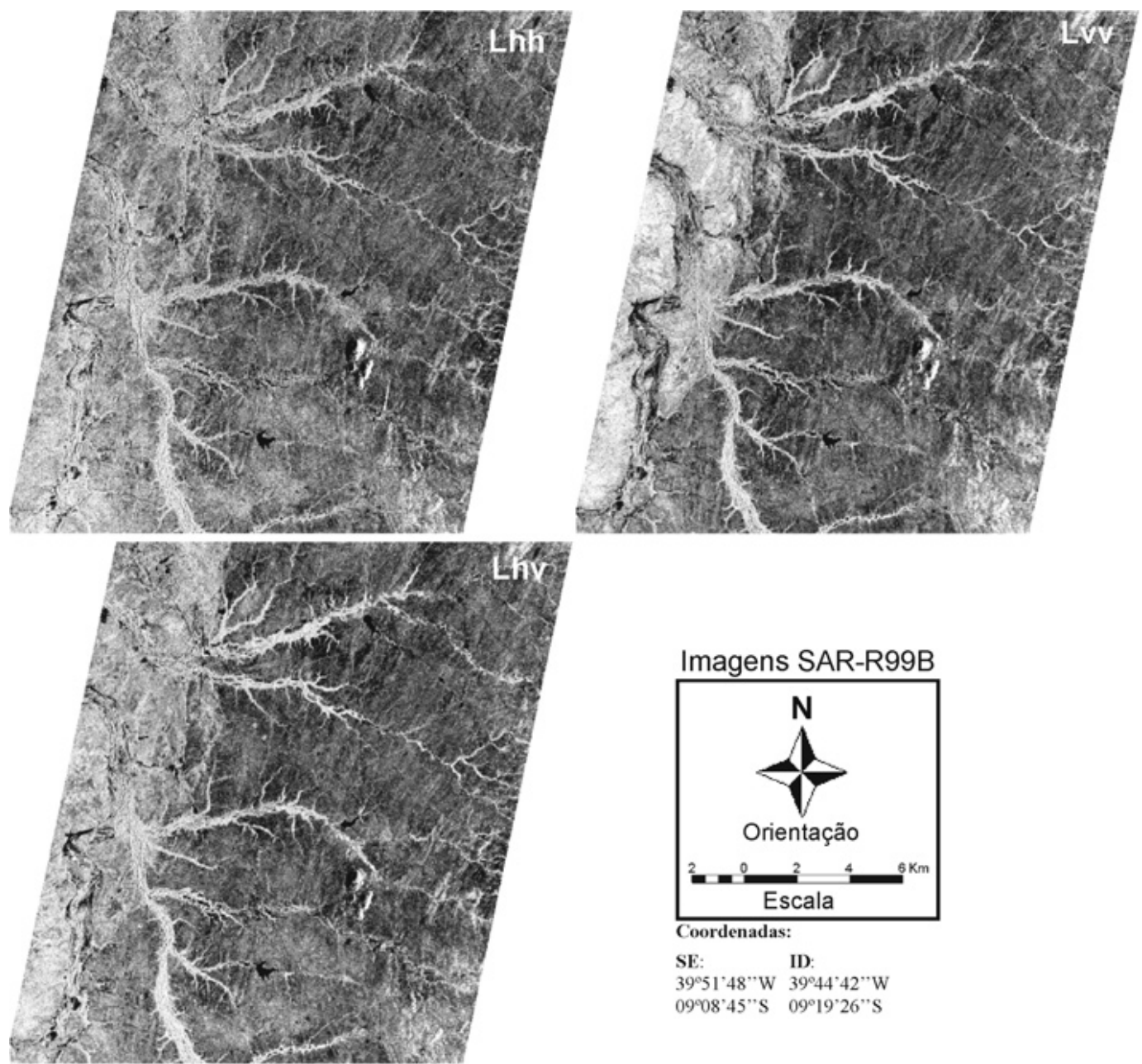

SE: $\quad$ ID

$39^{\circ} 51^{\prime} 48^{\prime \prime}$ "W 39०44.42"W

$09^{\circ} 08^{\prime} 45^{\prime \prime} \mathrm{s}$ 0919'26"s

Figura 4 - Imagens multipolarizadas L-HH, L-VV e L-HV do SAR-R99B da área de estudo. 
distintas, sendo resultante da integração das zonas homólogas de drenagem (Fig. 5a), de relevo (Fig. 5b) e de tonalidade (Fig. 5c). Os sedimentos aluvionares (em branco nos mapas), por serem igualmente bem caracterizados nas três polarizações, não foram considerados nesta avaliação comparativa. A relação entre todas as ZH's identificadas após a integração é apresentada na tabela 1.

A partir da rede de drenagem foi possível compartimentar as ZH's de ocorrência mais abrangente na área (Fig. 5a). Das seis ZH's identificadas, cinco foram confirmadas pela análise do relevo, identificadas como a, b, c, d, f (Fig. 5b). Os limites da ZH-f e da ZH-g são definidos por quebras negativas de relevo, porém apenas a primeira foi identificada sobre a rede de drenagem. Somente as ZH's de drenagem I, II e III refletiram variações de brilho distintas entre si, sendo identificadas na análise de tonalidade como A, B+E e C, respectivamente (Fig. 5c). As ZH's de drenagem IV, V e VI foram identificas como uma única $\mathrm{ZH}$ (D), pois não refletiram variações significativas de tonalidade entre si. As maiores contribuições do elemento tonalidade foram as ZH's F, G, H e $\mathrm{I}$, as quais não realçam variações significativas nas pro- priedades da rede drenagem e de relevo, por ocorrerem em áreas bastante restritas. A ZH-K foi unida à $\mathrm{ZH}-5$ no mapa de fotoanálise, por não resultar em alterações diagnósticas na rede drenagem e no relevo, mesmo ocorrendo em uma área não muito restrita.

A figura 6 apresenta os mapas de ZH's de drenagem (Fig. 6a), de relevo (Fig. 6b) e de tonalidade (Fig. 6c) e o mapa de fotoanálise integrado (Fig. 6d) referentes à imagem SAR de polarização L-VV. A relação entre todas as ZH's identificadas após a integração é apresentada na tabela 2 .

As seis $\mathrm{ZH}^{\prime}$ 's definidas pela rede de drenagem (Fig. 6a) coincidem com sete ZH's de relevo (Fig. 6b), isso porque a $\mathrm{ZH}-\mathrm{II}$ equivale a duas $\mathrm{ZH}^{\prime}$ s distintas: b e $\mathrm{g}$ (definida por quebra negativa). Além destas, h e i são adicionadas as sete $\mathrm{ZH}^{\prime}$ s de relevo já existentes, ambas também produtos da delimitação de quebras negativas. Apesar das quinze ZH's identificadas pelas propriedades de tonalidade (Fig. 6c), apenas as ZH's A, E e J têm equivalência precisa com ZH-I (drenagem) e ZH's G e I (relevo). A ZH de drenagem II (porção noroeste) corresponde a três tonalidades diferentes na imagem (ZH's
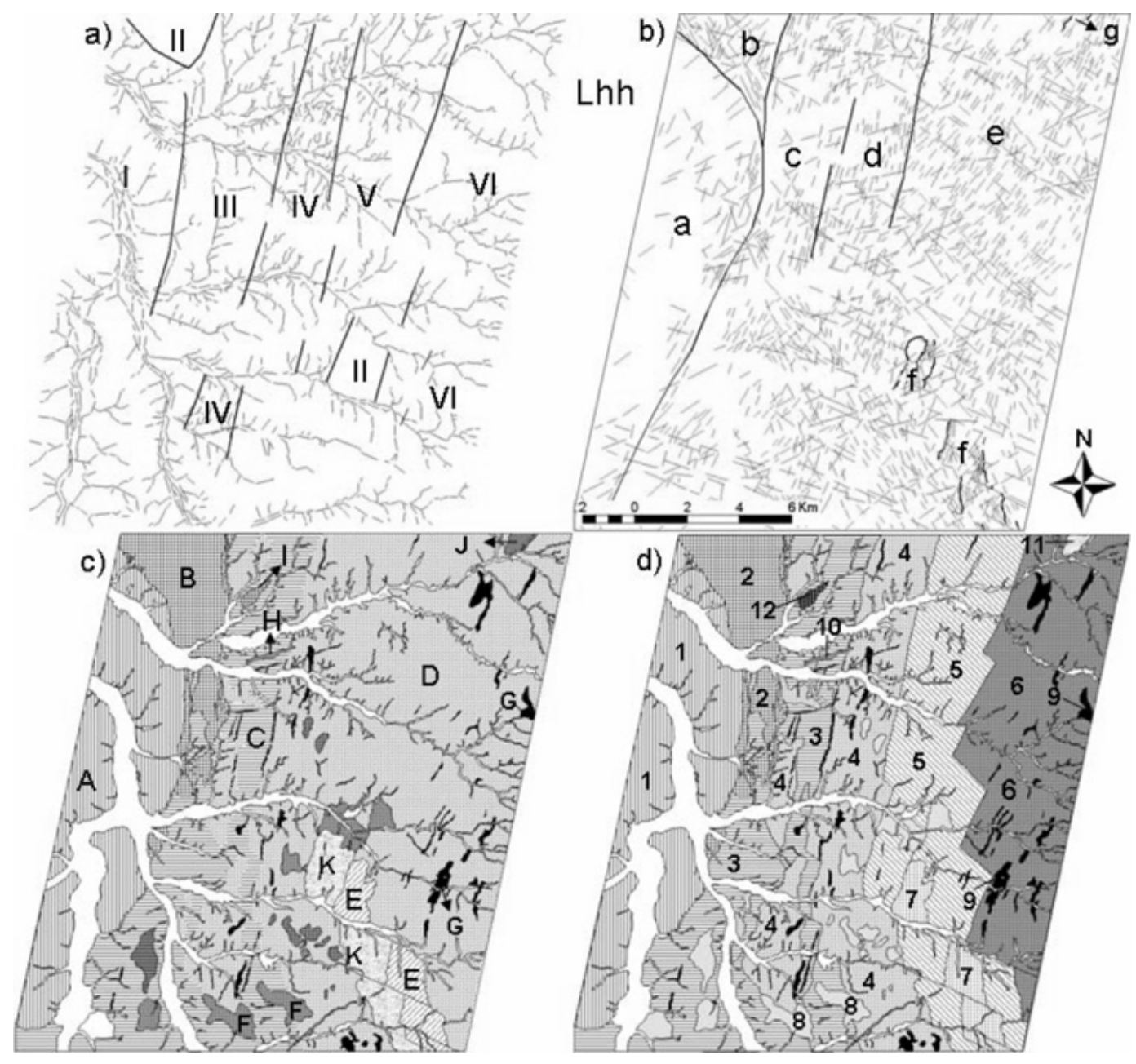

Figura 5 - Mapas de zonas homólogas de drenagem (a), de relevo (b), de tonalidade (c) e mapa de fotoanálise (d) obtido pela integração dessas zonas homólogas, referente à imagem de polarização $\mathrm{L}-\mathrm{HH}$. 
Tabela 1 - Relação entre as zonas homólogas integradas e as zonas homólogas dos elementos texturais (polarização L-HH).

\begin{tabular}{c|c|c|c}
\hline ZH integrada & ZH drenagem & ZH relevo & ZH tonalidade \\
\hline 1 & I & a & A \\
\hline 2 & II & b & B \\
\hline 3 & III & c & C \\
\hline 4 & IV & d & D \\
\hline 5 & V & e & D/K \\
\hline 6 & VI & e & D \\
\hline 7 & II & f & E \\
\hline 8 & - & - & F \\
\hline 9 & - & - & G \\
\hline 10 & - & - & H \\
\hline 11 & - & - & J \\
\hline 12 & - & - & I \\
\hline
\end{tabular}

B, K e N). As ZH's de drenagem III, IV e V resultaram em tonalidades semelhantes entre si. Deste modo, foram englobadas na $\mathrm{ZH}-\mathrm{C}$, com exceção de algumas porções de tonalidades levemente mais escuras (ZH-O). A ZH-VI refletiu uma tonalidade um pouco mais escura do que as ZH's III, IV e V e equivale, em parte, à tonalidade da ZH-D. A integração das informações obtidas pelas propriedades de drenagem, relevo e tonalidade gerou quinze $\mathrm{ZH}^{\prime}$ 's distintas (Tab. 2).

A figura 7 apresenta os mapas das $\mathrm{ZH}^{\prime}$ s da rede drenagem (Fig. 7a), do relevo (Fig. 7b), da tonalidade (Fig. 7c) e o mapa resultante da integração destas ZH's (Fig. 7d), referentes à imagem de polarização L-HV. A relação entre todas as ZH's identificadas após a integração é apresentada na tabela 3.

Das seis ZH's identificadas sobre a rede de drenagem (Fig. 7a), as ZH's I, III e IV tem correspondência espacial com as ZH's a, c e d do mapa de relevo (Fig. 7b). A ZH-II engloba duas ZH's de drenagem (b e f). As ZH's de drenagem V e VI correspondem a ZH-e de relevo. A análise da tonalidade contribuiu com mais
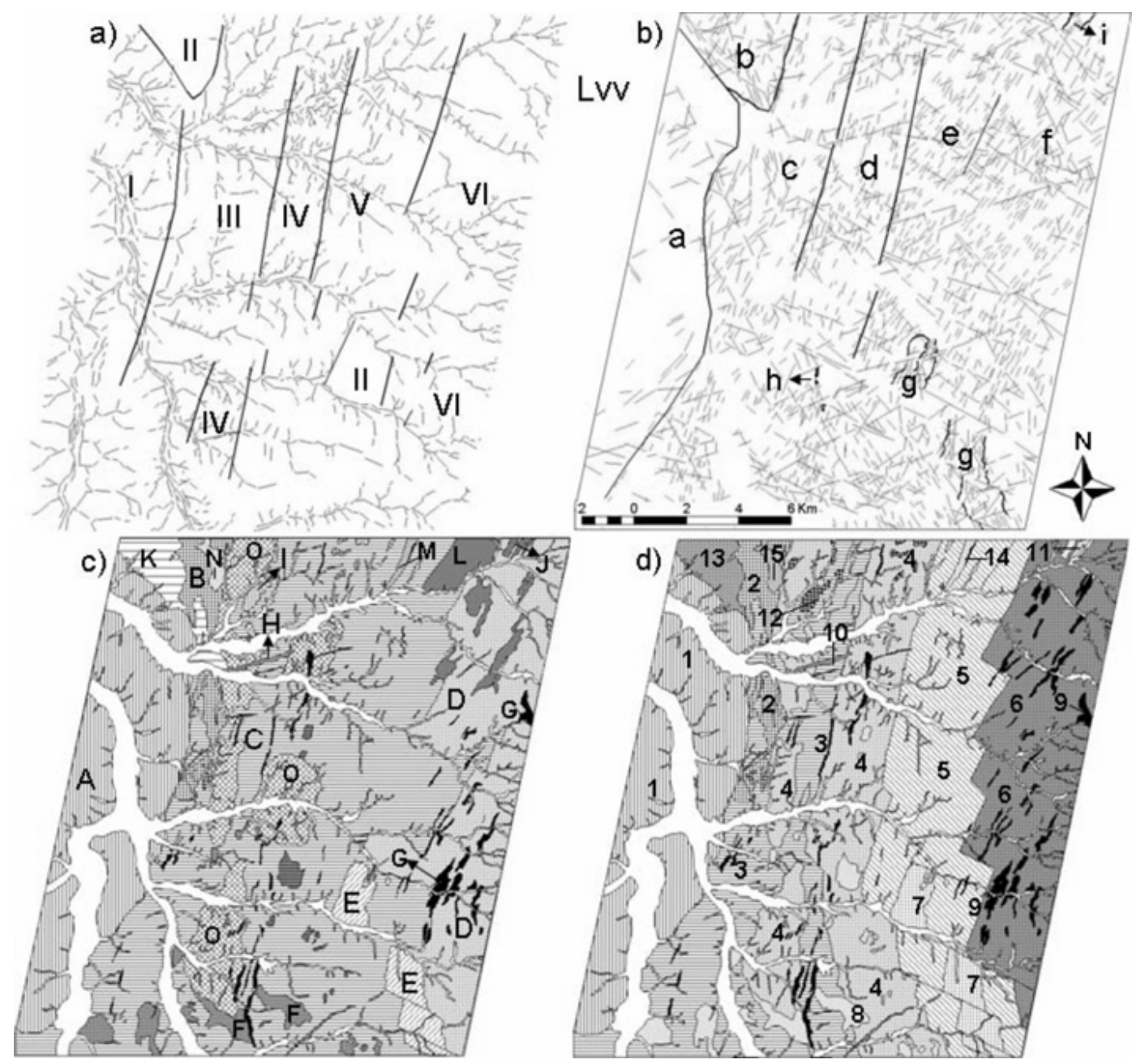

Figura 6 - Mapa de zonas homólogas de drenagem (a), de relevo (b), de tonalidade (c) e mapa de fotoanálise (d) obtido pela integração dessas zonas homólogas, referente à imagem de polarização $L-V V$. 
Tabela 2 - Relação entre as zonas homólogas integradas e as zonas homólogas dos elementos texturais (polarização $L-V V$ ).

\begin{tabular}{c|c|c|c}
\hline ZH integrada & ZH drenagem & ZH relevo & ZH tonalidade \\
\hline 1 & I & a & A \\
\hline 2 & II parcial & b & B \\
\hline 3 & III & c & C parcial \\
\hline 4 & IV & d & C parcial / O \\
\hline 5 & V & e & C parcial / L \\
\hline 6 & VI & f & D \\
\hline 7 & II parcial & g & E \\
\hline 8 & - & - & $\mathrm{F}$ \\
\hline 9 & - & $\mathrm{h}$ & $\mathrm{G}$ \\
\hline 10 & - & - & $\mathrm{H}$ \\
\hline 11 & - & $\mathrm{i}$ & $\mathrm{J}$ \\
\hline 12 & - & - & $\mathrm{I}$ \\
\hline 13 & II parcial & b parcial & $\mathrm{K}$ \\
\hline 14 & - & - & $\mathrm{M}$ \\
\hline 15 & II parcial & b parcial & $\mathrm{N}$ \\
\hline
\end{tabular}

sete ZH's (Fig. 7c), todas com ocorrências restritas, portanto de difícil caracterização pelas propriedades de drenagem e relevo. Ao todo, as ZH's integradas (Fig. 7d) somaram quatorze $\mathrm{ZH}^{\prime}$ s, duas a mais que as $\mathrm{ZH}^{\prime} \mathrm{s}$ referente à polarização L-HH (ZH-13 e ZH-14) e uma a menos que as ZH's referentes à polarização L-VV, que se refere a uma subdivisão da ZH-2 (Tab. 3).

A partir das informações apresentadas nos mapas de referência (Jordam 1968, Delgado \& Souza 1975, Paradella 1986) e dos dados coletados em campo, foi elaborada uma tabela com a associação de cada zona homóloga identificada e sua respectiva unidade litológica para cada polarização (Tab. 4).

As ZH's 8 (nas três polarizações), 13 e 14 (para as polarizações L-VV e L-HV), apesar de não estarem associadas a nenhum conjunto litológico nos mapas de referência, foram individualizadas por apresentarem variações tonais significativas em relação às unidades litológicas circunvizinhas. As ZH's 9 e 10 foram consideradas distintas entre si principalmente por uma diferença na distribuição espacial (orientadas segundo NNE-SSW e NE-SW, respectivamente). Jordan
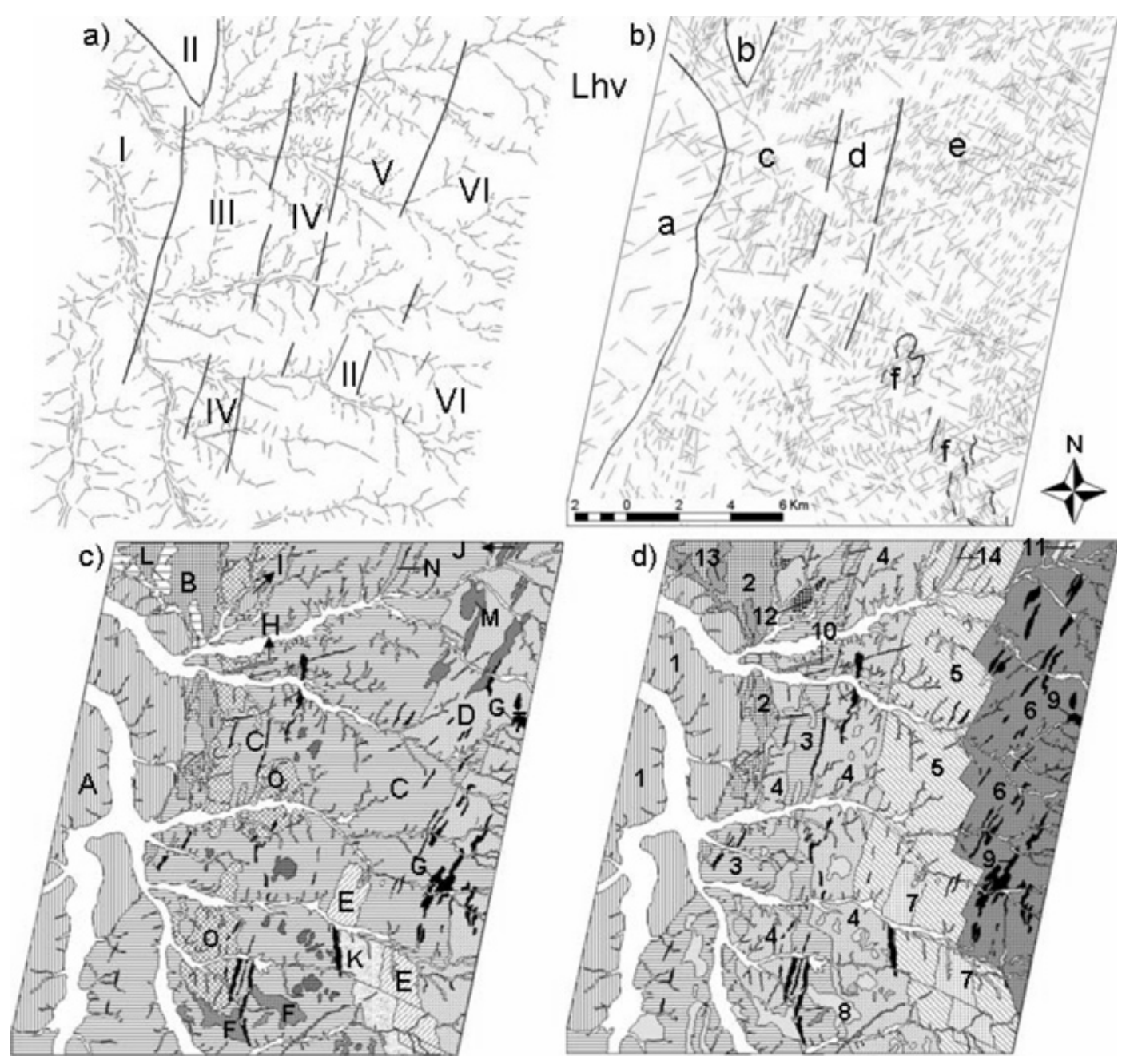

Figura 7 - Mapa de zonas homólogas de drenagem (a), de relevo (b), de tonalidade (c) e mapa de fotoanálise (d) obtido pela integração dessas zonas homólogas, referente à imagem de polarização $L-H V$. 
(1968) e Delgado \& Souza (1975) cartografaram-nas como unidades máficas (ZH-10) e ultramáficas (ZH-9) vinculadas a eventos geológicos distintos. A unidade ultramáfica tem grande importância econômica, pois é a unidade hospedeira da mineralização de cobre do Vale do Curaçá. Essas duas unidades foram definidas exclusivamente pelas tonalidades claras em relação ao seu entorno, apesar de apresentarem superfícies lisas e cobertura vegetal bastante esparsa (Fig. 8a). Segundo Mattoso (1975), em comum, ambas geram Vertissolos (Fig. 8b) com alto teor de argila $(60 \%$ a $90 \%)$ e elevada plasticidade, ou seja, forte contração quando secos e expansão quando úmidos, com alta capacidade de acúmulo de água. Uma precipitação pluviométrica mais elevada que o normal, como ocorreu no período que precedeu a aquisição das imagens (a estação agrometeorológica de Mandacaru da EMBRAPA, a $30 \mathrm{~km}$ da área de estudo, indicou um total de $85 \mathrm{~mm}$ para o intervalo de maio-junho de 2005, EMBRAPA 2006), resultou em solos com umidade, o que elevou o retroespalhamento do sinal de radar nessas áreas (Rabelo et al. 2007). Rochas cálcio-silicáticas descritas por Delgado \& Souza (1975) e Paradella (1986) e/ou rochas miloníticas com epidoto descritas por Jordan (1968) também foram englobadas na $\mathrm{ZH}-10$, pois não apresentaram diferenças na tonalidade nas três polarizações em relação às ultramáficas. A ZH-15, identificada apenas na imagem de polarização L-VV, foi associada aos calcários secundários, de idade cenozóica.

A partir do mapa de alinhamentos integrados de drenagem e de relevo (Fig. 9), da análise das demais propriedades de drenagem e de relevo das três polarizações e dados de campo e bibliográficos, cinco classes de estruturas foram definidas para a área:

1- Zona de cisalhamento rúptil sinistral de direção orientada no intervalo $\mathrm{N} 60^{\circ}-70^{\circ} \mathrm{W}$. É uma das mais evidentes, com ocorrência na porção leste-sudeste da área;

2- Foliações com direções principais segundo $\mathrm{N} 10^{\circ}-20^{\circ} \mathrm{E}$ e $\mathrm{N} 30^{\circ}-40^{\circ} \mathrm{E}$ ao norte, convergindo para $\mathrm{N} 20^{\circ}-30^{\circ} \mathrm{W}$ e $\mathrm{N} 30^{\circ}-40^{\circ} \mathrm{W}$ ao sul. São muito bem definidas nas imagens através de feições lineares sistemáticas, acompanhando o eixo de simetria da drenagem principal (Rio Curaçá) (Fig. 10). Essa variação de orientação foi diagnóstica na separação entre as unidades compostas por migmatito e por biotita-hiperstênio gnaisse;

3- Fraturas com direções ENE-WSW e WNWESE;

4- Falhamentos de empurrão com direção aproximada NNE-SSW. São representados nas imagens por alinhamentos geralmente arqueados. Angelim \& Kosin (2001) interpretam a ocorrência das unidades neoproterozóicas como klippe nas demais unidades paleoproterozóicas;

5- Foliações cataclásticas ou miloníticas, pouco expressivas nas imagens, paralelas a zona de cisalhamento rúptil sinistral $\mathrm{N} 60^{\circ}-70^{\circ} \mathrm{W}$.

Os resultados obtidos, integrados aos dados de campo e bibliográficos, permitiram uma avaliação quanto ao desempenho das polarizações no mapeamen-
Tabela 3 - Relação entre as zonas homólogas integradas e as zonas homólogas dos elementos texturais (polarização $L-H V$ ).

\begin{tabular}{c|c|c|c}
\hline ZH integrada & ZH drenagem & ZH relevo & ZH tonalidade \\
\hline 1 & I & a & A \\
\hline 2 & II parcial & b & B \\
\hline 3 & III & c parcial & C parcial \\
\hline 4 & IV & d & C parcial / O \\
\hline 5 & V & e parcial & C parcial / K \\
\hline 6 & VI & e parcial & D parcial / M \\
\hline 7 & II parcial & $\mathrm{f}$ & $\mathrm{E}$ \\
\hline 8 & - & - & $\mathrm{F}$ \\
\hline 9 & - & - & $\mathrm{G}$ \\
\hline 10 & - & - & $\mathrm{H}$ \\
\hline 11 & - & - & $\mathrm{J}$ \\
\hline 12 & - & - & $\mathrm{I}$ \\
\hline 13 & II parcial & $\mathrm{c}$ parcial & $\mathrm{L}$ \\
\hline 14 & - & - & $\mathrm{N}$ \\
\hline
\end{tabular}

Tabela 4 - Associação das zonas homólogas com as unidades litológicas dos mapas de referência, para cada polarização.

\begin{tabular}{|c|c|c|c|}
\hline $\mathrm{ZH}$ & L-HH & L-VV & L-HV \\
\hline 1 & $\begin{array}{l}\text { mica xisto e filito } \\
\text { subordinado }\end{array}$ & idem & idem \\
\hline 2 & mármore & idem & idem \\
\hline 3 & $\begin{array}{l}\text { biotita-hornblenda } \\
\text { gnaisse }\end{array}$ & idem & idem \\
\hline 4 & migmatitos & idem & idem \\
\hline 5 & $\begin{array}{l}\text { biotita-hiperstênio } \\
\text { gnaisse }\end{array}$ & idem & idem \\
\hline 6 & $\begin{array}{l}\text { quartzo-feldspato } \\
\text { gnaisse }\end{array}$ & idem & Idem \\
\hline 7 & sienito gnáissico & idem & Idem \\
\hline 8 & indefinida & idem & Idem \\
\hline 9 & ultramafitos & idem & Idem \\
\hline 10 & diques básicos & idem & Idem \\
\hline 11 & $\begin{array}{c}\text { mármores / mármore } \\
\text { com filitos }\end{array}$ & idem & Idem \\
\hline 12 & $\begin{array}{l}\text { elúvio arenoso } \\
\text { grosseiro }\end{array}$ & idem & Idem \\
\hline 13 & - & indefinida & Indefinida \\
\hline 14 & - & indefinida & Indefinida \\
\hline 15 & - & $\begin{array}{c}\text { calcário } \\
\text { secundário }\end{array}$ & - \\
\hline
\end{tabular}

to geológico. As informações sintetizadas na tabela 5 permitiram classificar a polarização L-VV como a de melhor desempenho, seguida de L-HV e, por último, de L-HH. 

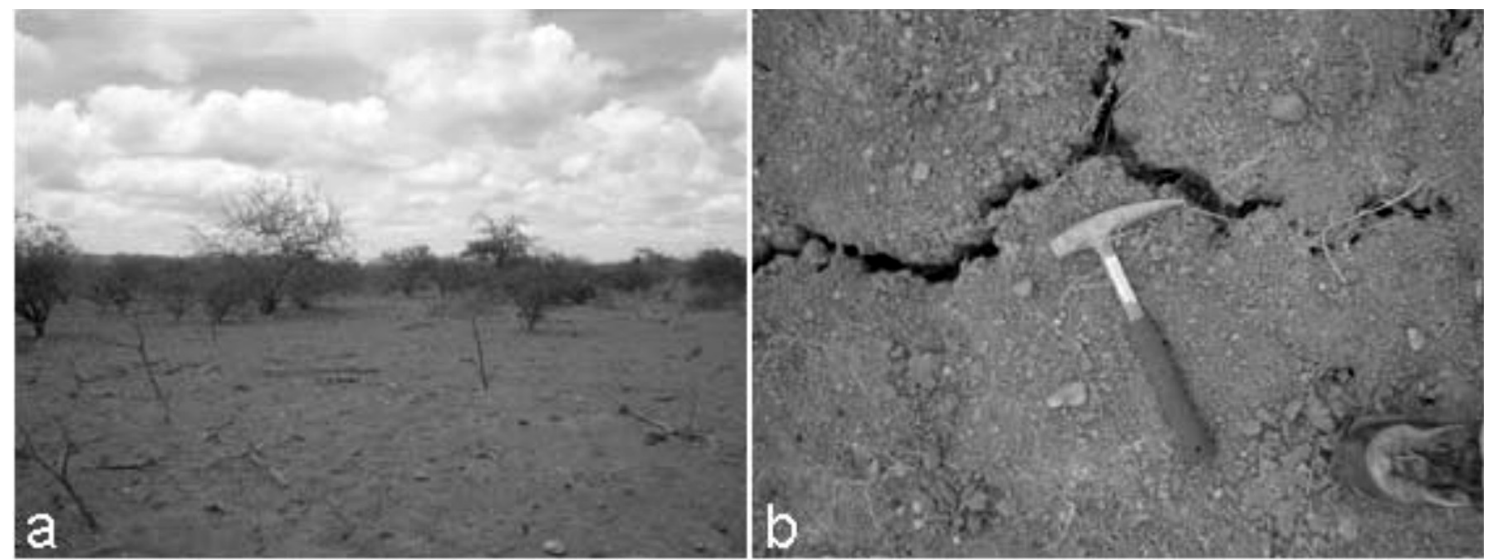

Figura 8 - Cobertura vegetal de caatinga esparsa, com raros fragmentos de rocha (a) e detalhe do Vertissolo (b), produto de alteração das unidades máfico-ultramáficas. Em b, detalhe das rachaduras pela forte contração dos Vertissolos.
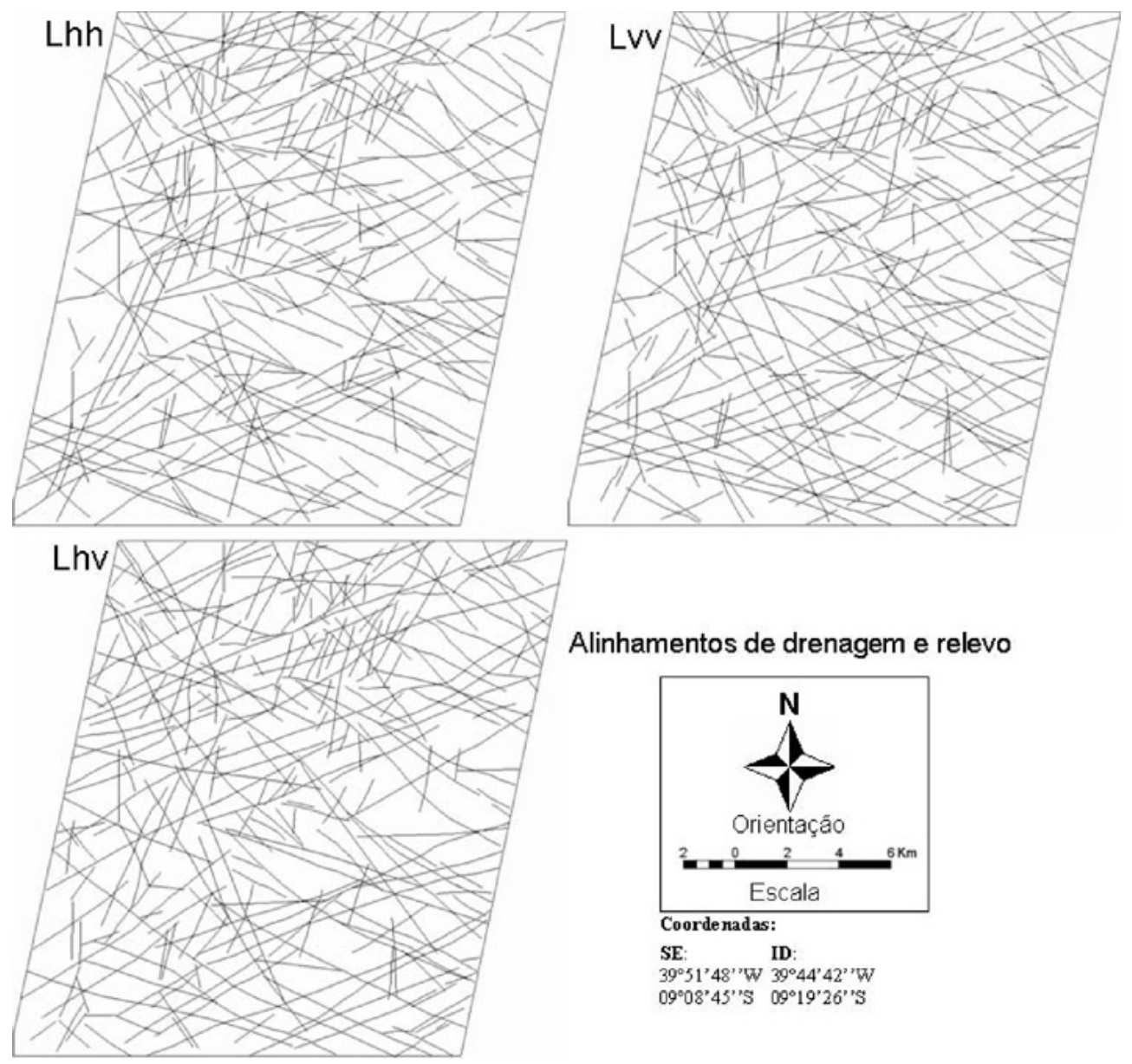

Alinhamentos de drenagem e relevo

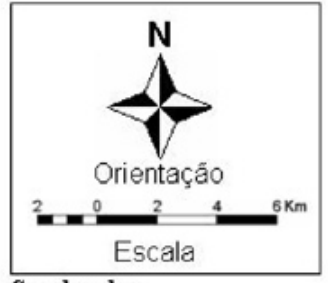

Coordenadas:

SE:

$39^{\circ} 51^{\prime} 48^{\prime}$ ' W $39^{\circ} 44^{\prime} 42^{\prime}$ 'W

$09^{\circ} 08^{\prime} 45^{\prime} \mathrm{S} \quad 09^{\circ} 19^{\prime} 26^{\prime} \mathrm{SS}$

Figura 9 - Mapa de alinhamentos obtidos pela integração dos alinhamentos de drenagem e relevo das polarizações $L-H H, L-V V$ e $L-H V$.

A imagem de polarização L-VV foi considerada a melhor pelo fato de ter proporcionado um maior detalhamento de zonas homólogas (15 no total) e, principalmente, por apresentar maior contraste de tonalidade entre algumas das mais representativas unidades fotoli- tológicas, como por exemplo, a unidade de ocorrência de mica-xistos (A na Fig. 11), a unidade de mármores e suas variações (B, C, D na Fig. 11) e a unidade de quartzo-feldspato gnaisses (F na Fig. 11). Na imagem da polarização L-HV também foi possível identificar 


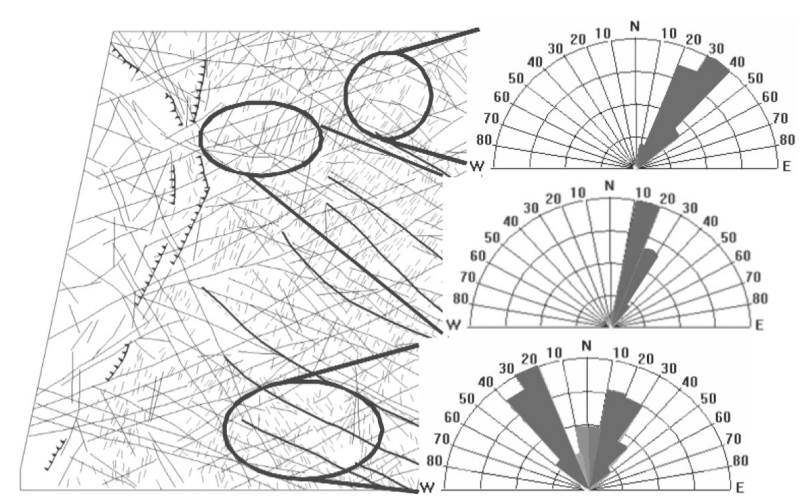

Figura 10 - Diagrama de rosetas de freqüência das foliações fotointerpretadas e digitalizadas a partir da imagem $L-V V$ nas três regiões com variações importantes de atitudes. Por resultarem em rosetas muito semelhantes, as demais polarizações não são apresentadas.

uma das variações dos mármores e quartzo-feldspato gnaisses (B e F na Fig. 11, respectivamente), mas com menor contraste tonal que na L-VV.

A tonalidade mais clara associada aos micaxistos na polarização L-VV (A na Fig. 11) em relação às outras imagens, pode ser explicada pela influência da densa cobertura vegetal de caatinga (em média $85 \%$ de recobrimento). Segundo Paradella \& Vitorello (1995), os principais tipos vegetais são quebra-faca, catingueira e faveleira de altura média que varia de 2 a 5 metros, com forte componente vertical (troncos e caules) influenciando as respostas na polarização L-VV, seguida por L-HV e L-HH (menos sensível aos componentes verticais do estrato vegetal). Assume-se que grande parte dessa cobertura se apresentaria como vegetação fotossinteticamente ativa (verde) devido à precipitação imediatamente anterior à época do imageamento, resultando na elevação dos valores de retroespalhamento pela presença da água na estrutura vegetal.

As ocorrências de mármores cartografadas pelos mapas de referência na porção noroeste da área foram segmentadas, pela análise da tonalidade, em três subunidades somente na imagem de polarização L-VV (B, C e D na Fig. 11). A polarização L-VV representou as três variações do conjunto rocha + solo + cobertura vegetal definidas em campo nessa região. A primeira é caracterizada pela ocorrência de afloramentos de mármores em lajedos decamétricos, com baixa cobertura vegetal e definida por uma tonalidade moderada em L-VV (C na Fig. 11). A segunda é marcada predominantemente por solos residuais de mármores, avermelhados, de superfícies lisas e com densa cobertura vegetal (principalmente catingueiras de 2 a $3 \mathrm{~m}$ de altura), definida por uma tonalidade relativamente clara na imagem L-VV (B na Fig. 11). A terceira é caracterizada como uma pequena elevação topográfica, sustentada por blocos centimétricos de mármores secundários e com densa cobertura vegetal (faveleiras e marmeleiros) de altura média entre 2 e $5 \mathrm{~m}$ (podendo chegar a $8 \mathrm{~m}$ ) com forte componen-
Tabela 5 - Desempenho das imagens multipolarizadas na análise visual. Os valores dos pesos considerados na análise foram: $1=$ ótimo; $0,75=$ bom; $0,5=$ moderado; $0,25=$ ruim; $0=$ não observado.

\begin{tabular}{|c|c|c|c|c|}
\hline Referência & Litounidades & L-HH & L-VV & L-HV \\
\hline $\begin{array}{l}\text { Delgado \& } \\
\text { Souza (1975) }\end{array}$ & $\begin{array}{l}\text { sedimentos } \\
\text { aluvionares }\end{array}$ & 1 & 1 & 1 \\
\hline “ & eluvio grosseiro & 0,25 & 1 & 0,75 \\
\hline $\begin{array}{c}\text { Jordan (1968); } \\
\text { Paradella (1986) }\end{array}$ & calcário secundário & 0 & 0,5 & 0 \\
\hline $\begin{array}{c}\text { Delgado \& } \\
\text { Souza (1975) }\end{array}$ & diques básicos & 0,5 & 0,5 & 0,5 \\
\hline “ & mica xisto & 0,25 & 1 & 0,75 \\
\hline “ & mármore & 0,25 & 1 & 0,75 \\
\hline “ & $\begin{array}{l}\text { biotita gnaisse } \\
\text { porfiroblástico }\end{array}$ & 0 & 0 & 0 \\
\hline “ & sienito & 1 & 1 & 1 \\
\hline “ & cálcio-silicatadas ${ }^{1}$ & 0 & 0,25 & 0 \\
\hline “ & anfibolito $^{1}$ & 0,25 & 0,25 & 0,25 \\
\hline “ & piroxenito / norito ${ }^{1}$ & 0,75 & 1 & 1 \\
\hline “ & $\begin{array}{l}\text { quartzo-feldspato } \\
\text { gnaisse (Bogó) }\end{array}$ & 0 & 0 & 0 \\
\hline “ & $\begin{array}{l}\text { biotita-hornblenda } \\
\text { gnaisse }\end{array}$ & 0,25 & 0,25 & 0,25 \\
\hline “ & migmatito & 0,5 & 0,5 & 0,5 \\
\hline “ & $\begin{array}{l}\text { biotita-hiperstênio } \\
\text { gnaisse }\end{array}$ & 0,5 & 0,5 & 0,5 \\
\hline $\begin{array}{c}\text { Paradella } \\
\text { (1986); Angelin } \\
\text { \& Kosin (2001) }\end{array}$ & $\begin{array}{l}\text { quartzo-feldspato } \\
\text { gnaisse (Bloco } \\
\text { Serrinha) }\end{array}$ & 0,5 & 0,75 & 0,75 \\
\hline \multicolumn{5}{|c|}{ Estruturas } \\
\hline- & $\begin{array}{c}\text { zonas de } \\
\text { cisalhamentos }\end{array}$ & 1 & 1 & 1 \\
\hline- & fraturas & 1 & 1 & 1 \\
\hline- & empurrão & 0,75 & 1 & 1 \\
\hline- & foliação & 1 & 1 & 1 \\
\hline \multirow[t]{2}{*}{ - } & $\begin{array}{l}\text { foliação milonítica } \\
\text { cataclástica }\end{array}$ & 0,75 & 1 & 1 \\
\hline & TOTAL & 10,25 & 14,5 & 13 \\
\hline
\end{tabular}

${ }^{1}$-Litotipos identificados como uma única classe nos mapas obtidos: máficoultramáficas

te vertical, definida por uma tonalidade muito clara na imagem L-VV (D na Fig. 11). O melhor desempenho da polarização L-VV pode ser explicado pela sua maior sensibilidade ao componente vertical característico da estrutura da vegetação no domínio do mármore secundário. Segundo Paradella \& Vitorello (1995), essa unidade possui, localmente, cobertura vegetal densa de baraúnas e quixabeiras, que podem atingir a altura de $10 \mathrm{~m}$, com rápida rebrotagem das folhas na época chuvosa. 


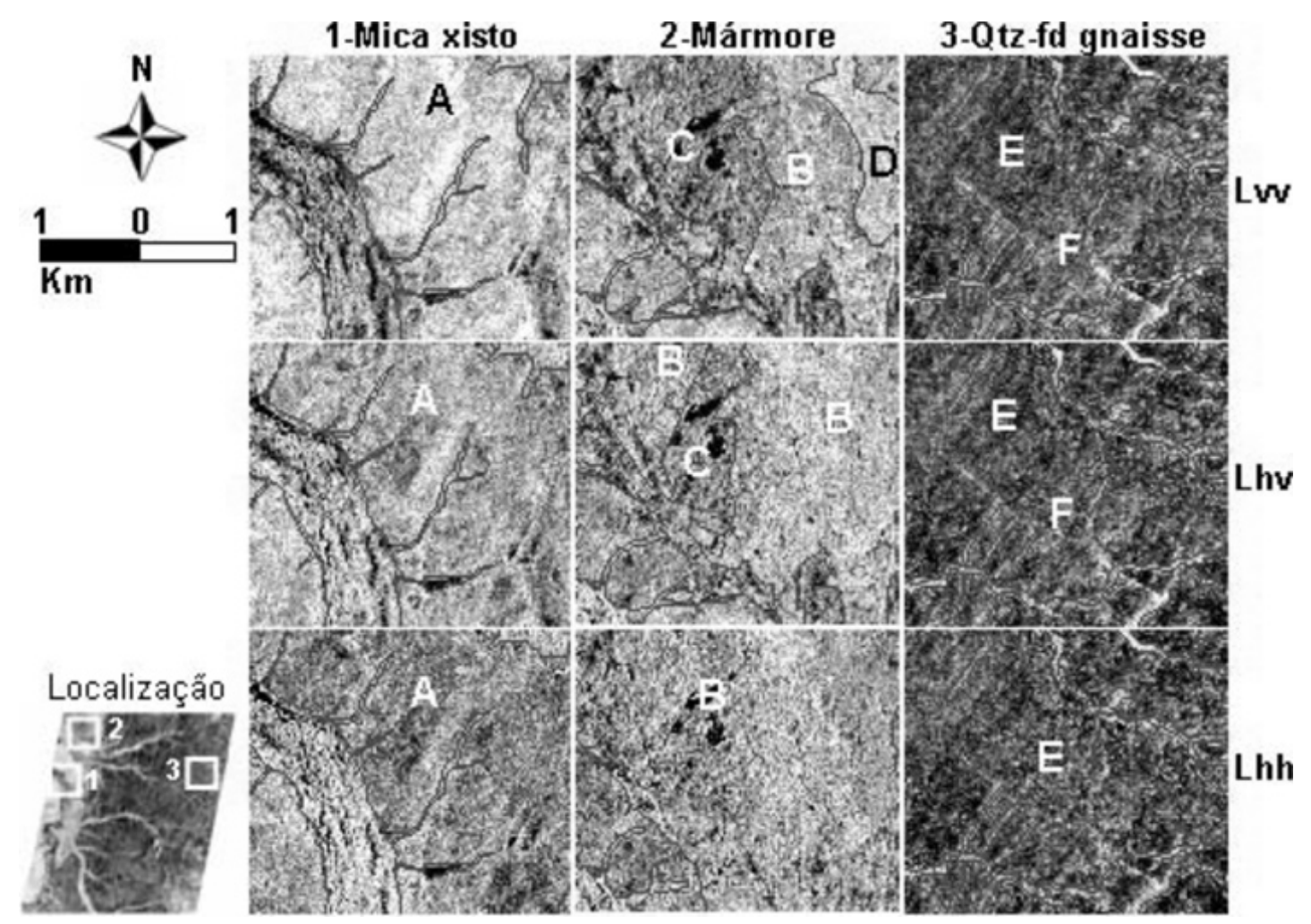

Figura 11 - Amostras de subáreas em cada polarização (L-VV na linha superior, L-HV na intermediária e L-HH na inferior) onde ocorrem as principais diferenças tonais. A primeira coluna é referente à região de mica xistos (A), a segunda é referente à região de mármores $(B)$, solos residuais $(C)$ e mármores secundários $(D)$ e a terceira refere-se às diferenças entre a tonalidade de biotita-hiperstênio gnaisses (E) e quartzo-feldspato gnaisses $(F)$.

Transformação por Componentes Principais (TCP) Com o objetivo de complementar a fotointerpretação das polarizações individuais, foram avaliadas composições coloridas resultantes do uso de técnicas de realce por ampliação linear de contraste (ALC) e pela Transformação por Componentes Principais (TCP). Como exemplo, apresentam-se os resultados obtidos para uma subárea com grande variabilidade litológica através da aplicação da TCP utilizando-se como input as três imagens originais polarizada mais a razão VV/HV. Das várias transformações aritméticas testadas (divisão e subtração), a razão VV/ $\mathrm{HV}$ foi a que apresentou o melhor resultado de realce.

Os parâmetros resultantes da TCP são apresentados na tabela 6 . A variância original das quatro imagens foi redistribuída nos três primeiros $\mathrm{CP}$, com quase $90 \%$ da informação total associada com o CP1, enquanto que a segundo e terceiro componentes concentraram aproximadamente $6 \%$ e $4 \%$ da informação original. A contribuição das imagens polarizadas e da razão em cada CP pode ser melhor analisada pelos auto-vetores da TCP (Fig. 12). No gráfico é possível observar que para o CP1 existe uma contribuição média (equivalente) das polarizações $\mathrm{HV}, \mathrm{VV}$ e $\mathrm{HH}$, e muito pouca contribuição da razão VV/HV. Para o CP2 a contribuição maior é das polarizações paralelas (HH e VV) e muito pouca contribuição de HV e da razão. Finalmente, a po-
Tabela 6 - Parâmetros resultantes da análise por componentes principais.

\begin{tabular}{c|c|c}
\hline Componentes & Auto-valor & Variância (\%) \\
\hline 1 & 10,1534 & $89,99 \%$ \\
\hline 2 & 0,6840 & $6,06 \%$ \\
\hline 3 & 0,4455 & $3,95 \%$ \\
\hline 4 & 0,0001 & $0,00 \%$ \\
\hline
\end{tabular}

larização cruzada (HV) domina a CP3, sendo subordinadas as contribuições de $\mathrm{HH}$ e VV.

A composição colorida da figura 13a, que combina os três componentes principais, exemplifica a aplicação da TCP em parte da área de estudo. A figura 13b mostra a composição colorida com os canais originais realçados por ALC.

A comparação entre as composições coloridas confirma a melhoria no contraste de respostas de matiz/texturas associadas com a distribuição espacial das litounidades com a TCP. Por exemplo, o contraste observado entre as unidades biotita-hornblenda gnaisses (nuances avermelhadas, letra A) e migmatitos (nuances 


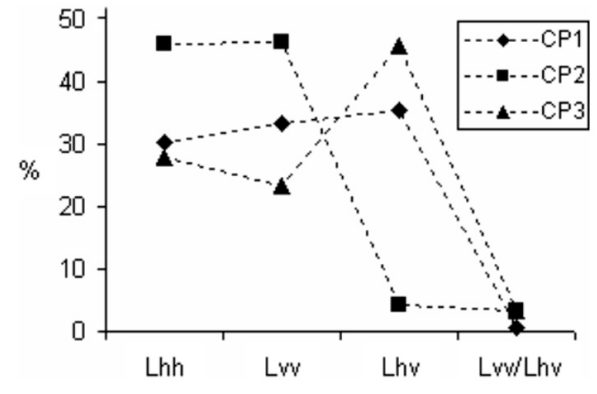

Figura 12 - Contribuição de informação das polarizações $H H, V V, H V e$ razão $V V / H V$ nos três primeiros componentes principais.

azuladas, letra B) é maior na TCP que na composição das imagens originais. Isto também é observado na comparação de respostas de biotita-hiperstênio gnaisses (nuances azul-verde e vermelho, letra $\mathrm{C}$ ) e quartzo-feldspato gnaisses (nuances dominantemente esverdeadas, letra D). As litounidades bem definidas na composição colorida das imagens polarizadas, como mica xistos (E), mármores $(\mathrm{F})$ e sienitos $(\mathrm{G})$, também permaneceram re-

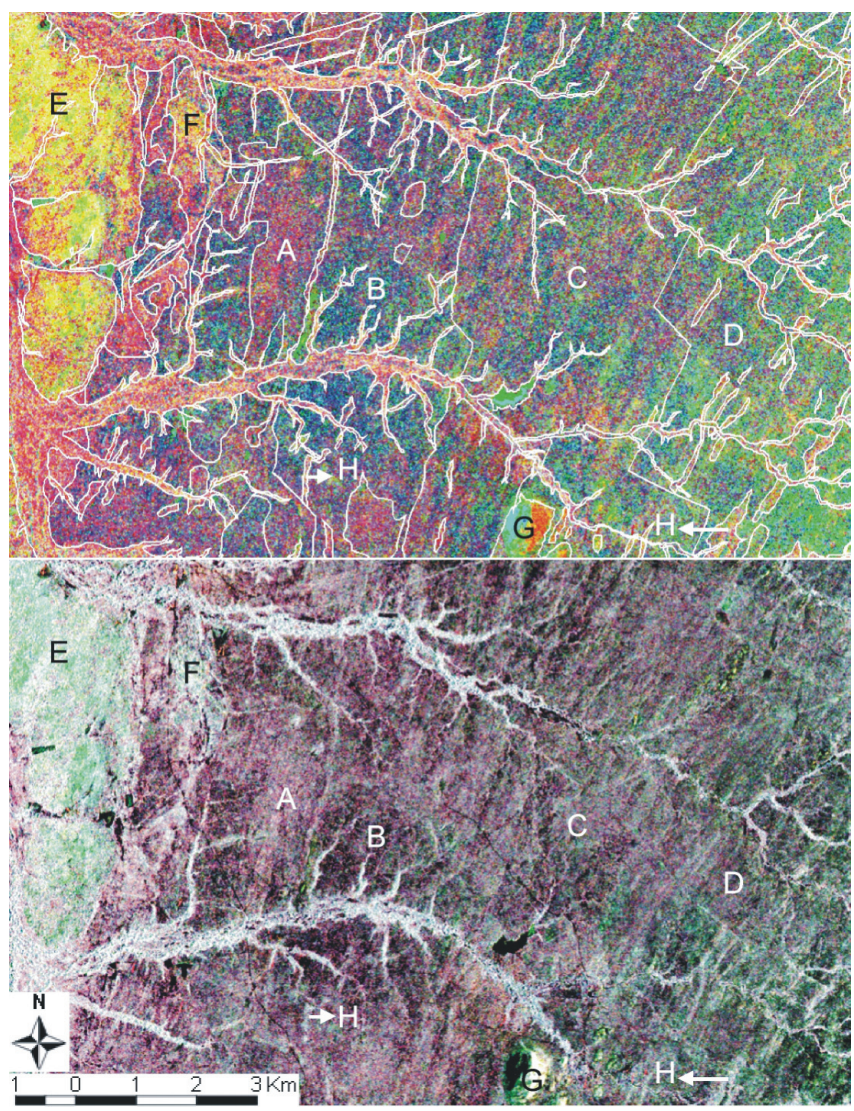

Figura 13 - Realces digitais das imagens multipolarizadas de parte da área de estudo. a) Composição colorida da TCP (CP1-R, CP2-G, CP3-B, com os contatos das litounidades interpretadas. b) Composição colorida de realce $A L C$ (HH-R, VV-G, HV-B) correspondente. alçadas na TCP (amarelo esverdeado, amarelo e verde/ alaranjado, respectivamente). Como aspectos negativos na TCP devem ser mencionados: a pequena diminuição no contraste entre unidades máfico-ultramáficas $(\mathrm{H}) \mathrm{em}$ relação às unidades vizinhas e a perda de definição das estruturas (foliações e fraturas).

Mapa Geológico Interpretado O produto final, obtido da integração dos dados de fotointerpretação das imagens multipolarizadas (canais individuais L-HH, L-VV e L-HV, composições coloridas), verificação de campo e dados bibliográficos prévios, é apresentado na figura 14 .

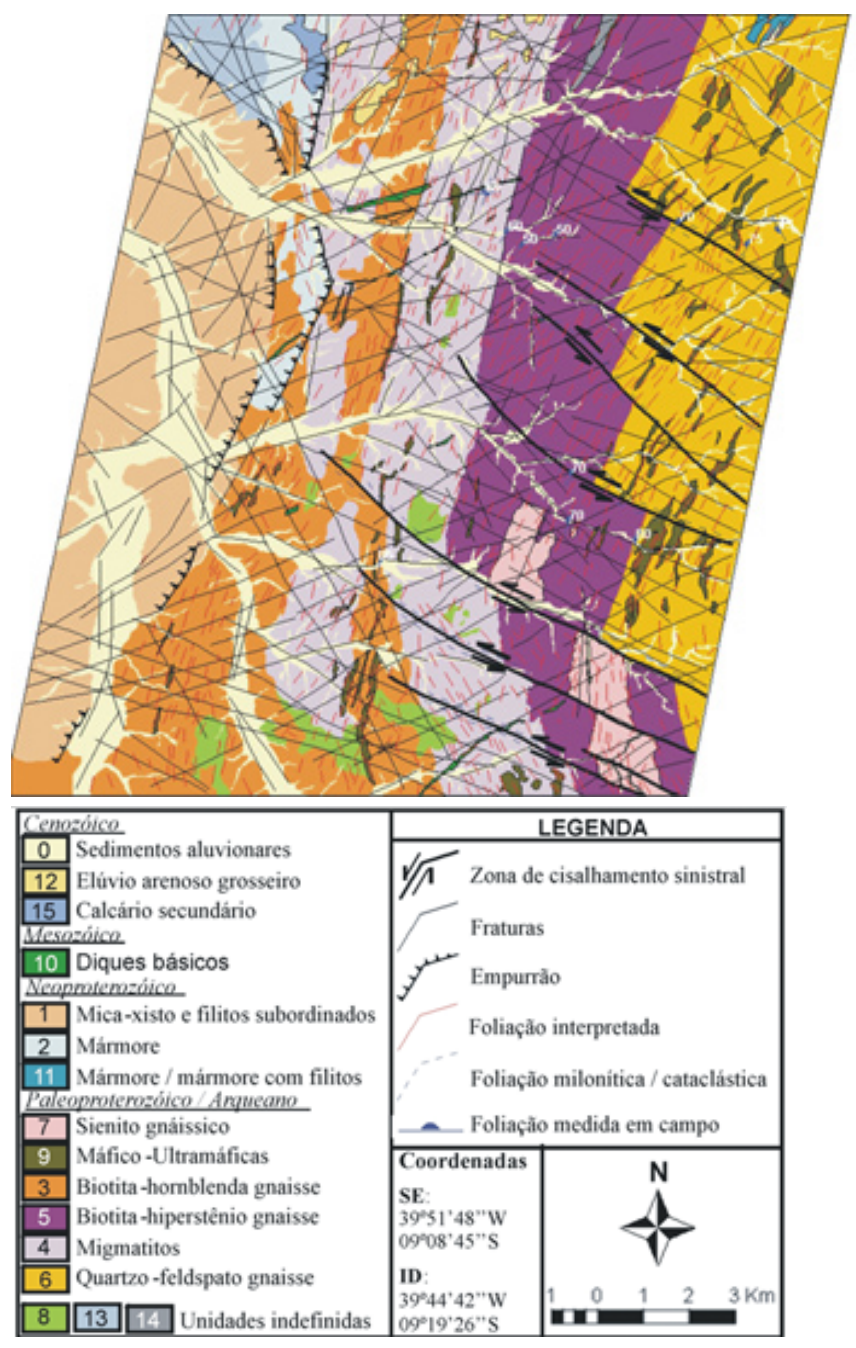

Figura 14 - Mapa Geológico obtido da interpretação das imagens SAR-R99B (originais, realçadas e transformadas), integrada com dados prévios e de campo (Fonte: Rabelo 2007).

CONCLUSÕES Os resultados da fotointerpretação geológica, da sua comparação com mapas preexistentes e com dados de campo, indicam a viabilidade de uso destas imagens como uma ferramenta valiosa em mapeamento na escala de detalhe (1: 50.000 ou maior). As informações extraídas dos vários produtos confirmam, 
integram e complementam o conhecimento prévio. A drenagem (prioritariamente) e o relevo foram os elementos texturais mais importantes na análise da fotointerpretação geológica. A tonalidade, embora de modo mais subordinado, foi também um elemento valioso na delimitação das diferentes unidades litotípicas.

A polarização paralela L-VV apresentou o melhor desempenho médio entre as polarizações, com maior detalhamento de zonas homólogas, devido ao maior contraste tonal/textural entre as unidades fotolitológicas de maior ocorrência na área (mica-xistos, quartzo-feldspato gnaisses) e ao maior detalhamento das unidades de ocorrências mais restritas (mármores, máfico-ultramáficas). As principais vantagens dessa polarização em relação às outras polarizações foram observadas nas propriedades texturais de relevo e de tonalidade. De acordo com a ordenação adotada na pesquisa, a polarização L-HV teve o segundo melhor desempenho na definição das unidades fotolitológicas, seguida pela polarização L-HH. Quanto à caracterização estrutural, as três imagens polarizadas tiveram um desempenho bastante similar, com uma pequena desvantagem da polarização L-HH, indicativa de contribuição maior do componente vertical da polarização nas imagens L-VV e L-HV no realce de estruturas. Vale ressaltar, também, que a ordenação quanto à qualidade das imagens de cada polarização é válida para as condições específicas em que se encontrava a área no período de aquisição, principalmente em relação à precipitação pluviométrica. A excelente qualidade radiométrica dos produtos calibrados, a elevada resolução espacial, e a alta sensibilidade das respostas em microondas às variações da rugosidade superficial (macro, micro-topografia) e da umidade, determinaram os resultados dessa análise. A continuidade dessa linha de pesquisa enfocará a avaliação de dados polarimétricos (amplitude e fase do sinal) em discriminação litológica através dos imageamentos realizados com os satélites ALOS/PALSAR (banda L) e RADARSAT-2 (banda C).

Agradecimentos Os autores agradecem ao Revisor da RBG; a FAB (COMGAR-cel. Nilo Andrade, CTA-IEAvmajor Veiga); ao CENSIPAM (Manaus) pela aquisição e processamento dos dados SAR-R99B e ao CENPESPetrobras (Dr. Fernando Pellon de Miranda) pelo auxílio na calibração MAPSAR. O primeiro e o segundo autores agradecem a CAPES e ao CNPq pelas Bolsas de Mestrado e Produtividade em Pesquisa, respectivamente.

\section{Referências}

Almeida F.F.M. 1977. O Cráton do São Francisco. Rev. Bras. Geoc., 7(4):349-364.

Angelin L.A.A. \& Kosin M. 2001. Programa Levantamentos Geológicos Básicos do Brasil - PLGB. Aracaju NWFolha SC.20-V, Estados da Bahia, Pernambuco e Piauí. Escala 1: 500.000. Texto Explicativo. CPRM/DIEDIG/ DEPAT (CCD 553.0981).

Barbosa J.S.F. \& Sabaté P. 2002. Geological features and the Paleoproterozoic collision of four Archean crustal segments of the São Francisco Craton, Bahia, Brazil: a synthesis. Anais da Acad. Bras. de Ciências, 74:343-359.

Barbosa J.S.F. \& Sabaté P. 2003. Colagem paleoproterozóica de placas arqueanas do Cráton do São Francisco. Rev. Bras. Geoc., 33(1-Suplemento):7-14.

Barbosa J.S.F., Sabaté P., Marinho M.M. 2003. O Cráton do São Francisco no Bahia: uma síntese. Rev.Bras. de Geoc., 33(1):3-6.

Barbosa J.S.F. \& Sabaté P. 2004. Archean Paleoproterozoic crust of the São Francisco Craton, Bahia, Brazil: geodynamic features. Precambrian Research,133(2004):1-27.

Cunha E.R.S.P., Santos A.R., Paradella W.R., Barros C.E.M., Veneziani P., Vale A.G. 2006. Integração de dados de radar, Aerogamaespectrométricos e geológicos nos domínios do Complexo Granítico Estrela, Província Mineral de Carajás. Rev. Bras. Geoc., 36(2):327-335.

Daily M., Elachi C., Farr T., Stromberg W., Williams S., Schaber G. 1978. Application of Multispectral Radar and Landsat Imagery to Geologic Mapping in Death Valley. NASA-JPL, 47p.

Delgado I.M. \& Souza J.D. 1975. Projeto Cobre Curaçá - Relatório Final - Geologia Econômica do Distrito Cuprifero do Rio Curaçá,Bahia, Brasil. 30 volumes, convênio DNPM/CPRM.

D'el-Rey Silva L.J.H. 1985. Geologia e controle estrutural do depósito cuprífero Caraíba, Vale do Curaçá, Bahia. Geologia e Recursos Naturais do Estado da Bahia. SME, Série Textos Básicos, v.6, p. 51-123.

D'el-Rey Silva L.J.H. 1996. Implication of the Caraiba deposit's structural controls on the emplacement of the Cu-bearing hypersthenites of the Curaçá Valley, BahiaBrazil. Rev. Bras. Geoc. 26(3):181-196.

EMBRAPA 2006. Tabela de precipitação pluviométrica mensal (mm) da Estação Agrometeorológica de Mandacaru (Juazeiro - Ba), 1975-2006. Empresa Brasileira de Pesquisa Agropecuária (EMBRAPA Semi Árido), Petrolina. Disponível em http://www.cpatsa.embrapa. br/servicos/dadosmet/cem-chuva.html. Acessado em 14/9/2006.

Evans D.L., Farr T.G., Ford J.P., Thompson T.W., Werner C.L. 1986. Multipolarization radar images for geologic mapping and vegetation discrimination. IEEE Transactions on Geoscience and Remote Sensing, 24(2):246257.

Ford J.P., Blom R.G., Coleman Jr. J.L., Farr T.G., Plaut J.J., Pohn H.A., Sabins Jr. F.F. 1998. Radar Geology. In: Henderson F. \& Lewis A. (eds.) Principles \& Applications of Imaging Radar, Manual of R. S.. 3rd. ed., N.Y., Amer. Soc. Phot. and R.S., John Wiley \& Sons Inc., p. 511-565.

Goulding M.M., Stevens D.R., Lim P.R. 2001. The SIVAM Airborne SAR System. In: IGARSS, Sydney, Australia, Proceedings, 6:2763-2765.

Hasui Y., D’el-Rey Silva L.J.H., Lima e Silva F.J., Mandetta P., Moraes J.A.C., Oliveira J.G., Miola W. 1982. Geol- 
ogy and copper mineralization of Curaçá Valley, Bahia. Rev. Bras. Geoc. 12(1-3):463-474.

Jordan H. 1968. O calcário bambuí e o Grupo Canudos na região de Curaçá, Bahia. Recife. Superintendência de Desenvolvimento do Nordeste (SUDENE), Boletim de Estudos 4, p. 59-63,

Lindenmayer Z.G. 1981. Evolução geológica do Vale do Curaçá e de corpos máfico-ultramáficos mineralizados a cobre. Dissertação de Mestrado, Universidade Federal da Bahia, Salvador, 140p.

Mattoso S.Q. 1975. Média móvel dos valores de cobre usada em prospeç̧ão geoquímica regional no Distrito Cuprifero de Caraíba, Bahia. Tese de Professor Titular, Universidade Federal da Bahia, Salvador, 144p.

Mura J.C., Correia A.H., Honda P. 2007. Calibração preliminar dos dados SAR polarimétricos em banda L do sensor R99B do CENSIPAM. In: INPE, Simp. Bras. Sens. Rem., 13, Florianópolis, Anais, p. 4951-4958.

Mura J.C., Paradella W.R., Dutra L.V., Santos J.R., Rudorff, B.F.T., Miranda F.P., Silva M.M.Q., Silva W.F. 2009. MAPSAR image simulation based on L-band polarimetric data from SAR-R99B airborne sensor (SIVAM System). Sensors, 9:102-107 (doi: 103390/s901001002).

Paradella W.R. 1986. O Significado litológico da informação espectral e temporal (sazonal) de dados digitais MSS do satélite Landsat-3 para o baixo Vale do Rio Curaçá, Bahia. Rev. Bras. Geoc., 16(2):135-148.

Paradella W.R. \& Vitorello I. 1995. Geobotanical and soil spectral investigation in the "caatinga" environment (Brazil) base on multitemporal remote sensing data. Can. Jour. of Rem. Sens., 21(1):52-59.

Paradella W.R., Santos A.R., Dall'Agnol R., Pietsch R.W.A. 1998. A geological investigation based on airborne (SAREX) and spaceborne (RADARSAT-1) SAR integrated products in the Central Serra dos Carajás Granite area, Brazil. Can. Jour. of Rem. Sens., 21(4):376-392.

Paradella W.R., Santos A.R., Veneziani P., Cunha E.S.P. 2005. Radares imageadores nas Geociências: estado da arte e perspectivas. Rev. Bras. Cartografia, 57(01):56-62.

Paradella W.R., Bignelli P.A., Veneziani P., Pietsch R.W., Toutin T. 1997. Airborne and Spaceborne Synthetic Aperture Radar (SAR) Integration with Landsat TM and gamma ray spectrometry for geological mapping in a tropical environment, the Carajás Mineral Province, Brazil. Int. Jour. of Rem. Sens., 18(7):1483-1501.

Paradella WR, Santos A.R., Veneziani P., Sant Anna M.V., Morais M.C. 2000. Geological investigation using RADARSAT-1 images in the tropical rain forest environment of Brazil. Can. Jour. of Rem. Sens. 26(2):82-90.

PCI GEOMATICS. 2005. Geomatica Focus User Guide. Geomática Version 10.0, Ontário, Canada: Richmond Hill.

Pedroso E.C., Rivard B., Crosta A.P., Souza Filho C.R., Miranda F.P. 2001. Reconnaissance geologic mapping in the Tapajós Mineral Province, Brazilian Amazon, using spaceborne SAR imagery and airborne geophysics. Can. Jour. of Rem. Sens., 27(6):669-678.

Quegan S. 1994. A unified algorithm for phase and cross-talk calibration of polarimetric data-theory and observations. IEEE Transactions on Geoscience and Remote Sensing, 32(1):89- 99.
Rabelo T.N. 2007. Avaliação das imagens multipolarizadas de radar em banda L do sensor SAR-R99B (SIVAMCENSIPAM) em aplicação geológica no Vale do Rio Curaçá, Bahia. Dissertação de Mestrado, Divisão de Sensoriamento Remoto, Instituto Nacional de Pesquisas Espaciais, São José dos Campos, 185 p.

Rabelo T.N., Paradella W.R., Santos A.R., Rennó C.D., Galvão L.S., Mura S.S., Knust S.S.A. 2007. Evaluating the discrimination of $\mathrm{Cu}$-mineralized rock alteration products from simulated MAPSAR images in the Curaçá Valley, Brazil. Intern. Jour. of Rem. Sens., 28(20):47014708 .

Santos A.R., Veneziani P., Paradella W.R., Morais M.C. 1999. A estereoscopia com imagens RADARSAT-1: uma avaliação na Província Mineral de Carajás. Rev. Bras. Geoc., 29(4):627-632.

Santos A.R., Veneziani P., Paradella W.R., Morais M.C. 2001. Radar aplicado ao mapeamento geológico e prospeç̧̃̃o mineral: Aplicações. Curso INPE/ADIMB, São José dos Campos, 21-26 de Agosto de 2000. São José dos Campos, INPE, 103p. (INPE-8117-PUD/45).

Santos A.R., Veneziani P., Paradella W.R. 2003. Avaliação da estereoscopia SAR (Standard-RADARSAT-1) e híbrida (Standard-RADARSAT-1 \& TM-Landsat 5) em mapeamento geológico na Província Mineral de Carajás. Rev. Bras. Geoc., 33(2-suplemento):153-160.

Schaber G.G. \& Berlin G.L. 1980. Terrain analysis procedures for modeling radar backscatter. In: NASA (ed.) Radar Geology: An Assessment. NASA-JPL, Pasadena, p.168-199.

Schröeder R., Puls J., Hajnsek I., Jochim F., Neff T., Kono J., Paradella W.R., Silva M.M.Q., Valeriano D.M., Costa M.P.F. 2005. MAPSAR: a small L-band SAR mission for land observation. Acta Astronautica, 56:35-43.

Teixeira W., Sabaté P., Barbosa J., Noce C.M., Carneiro M.A. 2000. Archean and Paleoproterozoic Tectonic Evolution of the São Francisco Craton, Brazil. In: Cordani U.G., Milani E.J., Thomaz Filho A., Campos D.A. (eds.) Tectonic Evolution of South America. IGC, 21, Rio de Janeiro, p. 101-137.

Teruyia R.K., Paradella W.R, Santos A.R, Dall'Agnol R., Veneziani P. 2008. Integrating airborne SAR, Landsat TM and airborne geophysics data for improving geological mapping in the Amazon Region: the Cigano Granite, Carajás Province, Brazil. Intern. Jour. of Rem. Sens., 29(13):3957-3974.

Veneziani P. \& Anjos C.E. 1982. Metodologia de interpretação de dados de sensoriamento remoto e aplicações em geologia. São José dos Campos, INPE, 61p. (INPE-2227 -MD/014).

Veneziani P., Santos A.R., Paradella W.R. 2004. A evolução tectono-estratigráfica da Província Mineral de Carajás: um modelo com base em dados de sensores remotos orbitais (SAR-c RADARSAT-1, TM Landsat 5), aerogeofísica e dados de campo. Rev. Bras. Geoc., 34(1):67-78.

Manuscrito ID 11686 Submetido em 14 de julho de 2008 Aceito em 12 de dezembro de 2008 Sistema eletrônico de submissão 